Journal of Social Sciences 6 (3): 389-392, 2010

ISSN 1549-3652

(C) 2010 Science Publications

\title{
The Design to Develop New Formats and Model Products for the Community
}

\author{
Ratthai Porncharoen \\ Faculty of Decorative Arts, Silpakorn University, Bangkok, Thailand 10200
}

\begin{abstract}
Problem statement: The manufacture of community needed to be designed in a new style so that it would be needed by the consumers. The objectives of this research were to study: (1) the former product design and creation of new product design, (2) the development of model book of new product for being disseminated to community and (3) the development of product model to community as well as presentation of performance for exhibition. Approach: The research area included Supan Buri, Chai Nat, Sing Buri, Lop Buri, Ang Thong, Auudtaya and Sara Buri Provinces. The samples as informants were selected by Purposive Sampling, for 50 persons. The instruments using for collecting data consisted of: The survey, questionnaire, interview, observation, focus group discussion and participatory workshop. Data were classified into groups, designed for creating new products, analyzed the appropriateness as the specified goal. The findings were presented in descriptive analysis. Results: The research findings, conceptual framework which would be used in designing the products were as follows: (1) the utility should be used more than one thing, (2) the model and color had to be remarkable and distinguished (Note: The design study focused on the shape of product), (3) the furniture study including the appliances and house decoration, the shape needed to be classic (simple) and modern), for the souvenir study, the shape should be classic, (4) the using material needed to obtain from the nature including the other materials as common factor which were available in the country as well as cheap and (5) the consideration in instrument and possibility for producer. Conclusion/Recommendations: The effect from this study development would be useful for different community groups that could be used for developing work and modified or expanded in creating the new product for future product.
\end{abstract}

Key words: Design, develop, new formats, model products, community

\section{INTRODUCTION}

In recent situation, Thailand faced with Economic problem from export sector. As a result, the national income decreased since the occurred economic condition all over the world in the present. According to these effects, the crisis was entered. Consequently, there were hundred thousands unemployed workers. It was expected that there would be one million unemployed workers this year, especially in labor groups of industrial sector lowering their production or quit enterprises for large amount of number. In addition, the viewpoint in community item production including the labor throughout country with higher number, also faced with problem since the produced items were difficult to be sold or couldn't be sold because most of people reduced their expenditure.

To solve problem from national crisis in 1997, before this, His Majesty the King's Sufficiency Economy Philosophy was used as philosophy for national management. Consequently, the country could survive from that crisis. In national development, the community of grass root was viewed. Moreover, the continuous performances were created for developing the strength of community leading to sustainably well being and happy.

According to Sufficiency Economy Philosophy in 1997 (Krongkaew, 2003) the researcher focused on guidelines for working including conceptual framework from the design by viewing the competency of community groups and using natural local material before such as bamboo, rattan, water-hyacinth and other kinds of local material, for usefulness. The materials in Central Region using for producing the supply, was studied in order to know the characteristics and utilize them in designing the products as well as applying with readymade cheap material producing in the country for designing by adding originality for the products.

\section{MATERIALS AND METHODS}

Seven provinces were research area including: Supan Buri, Chai Nat, Sing Buri, Lop Buri, Ang Thong, Auudtaya and Sara Buri Provinces Provinces. For this 
study, Qualitative Research Methodology was administered. Data were collecting from the samples were selected by Purposive Sampling from the producers of OTOP, community leaders, product sales and consumers, total of 570 persons. The instruments using for collecting data were the Interview Form, Observational Form, Focus Group Discussion and Participatory Workshop. Data were investigated for the consumers' need and producers' potentiality analyzing for producing the new model products. Qualitative Data were analyzed and presented in descriptive analysis.

\section{RESULTS}

According to the search for information in product model as well as information from the producer and consumers sources, the overall findings could be concluded as follows:

- The conclusions from studying in the former product model, found that most of community product models were similar or the same. Most of them lacked of fitting in the usage affecting beauty, especially the appliance items, raw materials weren't processed. As a result, the study patterns were stiff without beauty as well neatness in some kind goods, compared with the products producing from industrial instruments

- The conclusions by analyzing from consumer groups, found that: (1) most of persons who could afford to buy the items, were females with the age from 35 years old and up. Those who were 46 years old being able to buy in highest level, (2) most of buyers often bought local products from the organized exhibition, (3) most of the designed products could be easily sold including the selling price not more than 1,000 baths/piece. It would be more easily sold when it should be 500 baths/piece and lower, (4) the good product design had to make the buyers not to compare the price, (5) the items with different shapes and colors would have distinguished from the same kind of items, would create an opportunity in selling more, (6) the items which could be various utilities in themselves or in the same product, would be able to be sold more, (7) the article and house decoration items were the ones with the amount of buying more than a half of furniture items, the small amount of items were souvenirs, (8) the furniture items, most of buyers wanted the simple classic model as well as modern. The product colors were natural tones as well as bright tone. The used materials came from nature including other kinds of material, (9) the article and house decoration items, most of buyers wanted the simple classic model. Only some groups wanted the modern ones. For the color tone, it should be natural tone and bright tone. The used materials should came from nature including other kinds of material and (10) the souvenir items, most of buyers wanted simple classic model. Only some groups needed For the color of product, it should be bright and natural tone. The used material should obtained from the natures

- The conclusions from surveying the producer groups, found that: (1) the designed product should be served with general basic instruments, (2) the designed product should be original with various utilities and (5) the designed product should make general people could make it

- The producers' general wishes were: (1) the market or customer wanted, (2) the capital supported by government, (3) the OTOP exhibition or selling wanted to be supported by the government and (4) the need in instrument such as hydraulic oven, bamboo, Mack shooting for fixing the product

\section{DISCUSSION} follows:

According to the findings, could be discussed as

- According to conceptual framework from conclusions, could be determinants in designing and developing the new products in order to be on foundation of real desire, would be focused on the consumers' need and community products. For the design, the researcher designed until the final process with more than 100 product models in order to create the model study piece of furniture. It was supported by Shimizu (1990) drawing technique by drawing picture with major design as standard structure in creating the product picture by determining the perspective point and real distance on structure based on the wanted position. The obtained usefulness by drawing the product scenery from this structure, the correct and clear size would be obtained. But, there would be difficulties in determining the space on using for designing. In addition, the researcher studied relationship of Hubel and Lussow (1984) and Doblin (1950) picture drawing with determination the characteristic of structuire box in drawing picture as Bird' Eye View at 30 and $60^{\circ}$. The usefulness from this theory, was adequate with application in designing because the clear drawing space could bge determined. But, most of drawing 
performances, would be error. As a result, incorrect proportion of products picture were obtained. Therefore, the researcher studied by applying the received theory in comparing with the modeled theory in drawing perspective picture used by Landry. According to the above guidelines, the researcher applied these theories to be easier by determining view angle at the base in creating picture with steps in drawing by determining the box of standard picture as Fig. 1 in order to help in thinking and drawing the sketch picture quicker (Poncharoen, 2003)

- The application in principle of the industrial product design in analyzing the information in order to be used in various kinds of work regarding to Function of product for determining the usefulness of product work usage by trying to design the product with various functions as well as including the information of Customer/User and Market by studying from the customers' taste and need ( from the information survey ) as well as the need in utility whether it would be the work function, model and beauty, color and price in which would be used as criterion in setting the selling price in order to be used in designing and creating the real work piece with worthwhile appropriate profit with producer. For these processes, the researcher had to see the Mass Production with standard of the same products. Moreover, the design should be in trend of market in order to create the model, Earle $(1990 ; 2004)$ design process for decision making was administered by the researcher

- It started from Problem Identification by studying different kinds of information in order to obtain the problem situation or real need for using as conceptual framework in designing. Later on, the Preliminary Ideas in working was the search for drawing the sketch picture of designed product by thinking in the framework of major determined approach Fig. 1 as well as Design Refinement used by the researcher: The attempt in choosing the sketch with good point in different parts from many sketch patterns in order to be improved again in Analysis Process by brining these good points for sketching together by using principle of design for creating beauty. Then, the Decision Making Process was entered by using principle of design and product design as criterion in selecting (Fig. 2). But, for some kinds of work, for instance, beauty or system work, the specialists in those field should make decision. In case of beauty, Working Group should be administered by the experts helping in making decision.

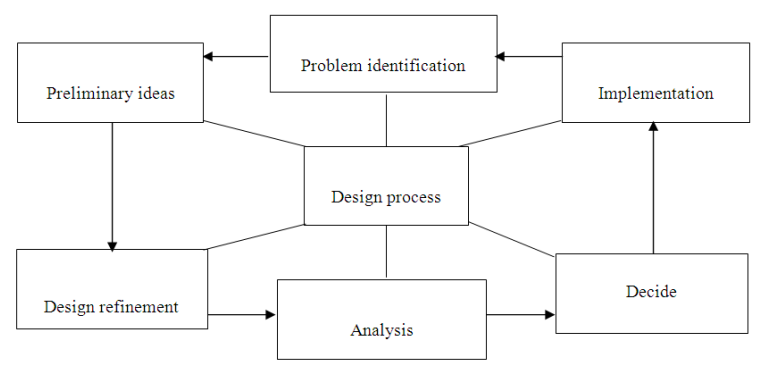

Fig. 1: The steps of Earle's design process, was shown
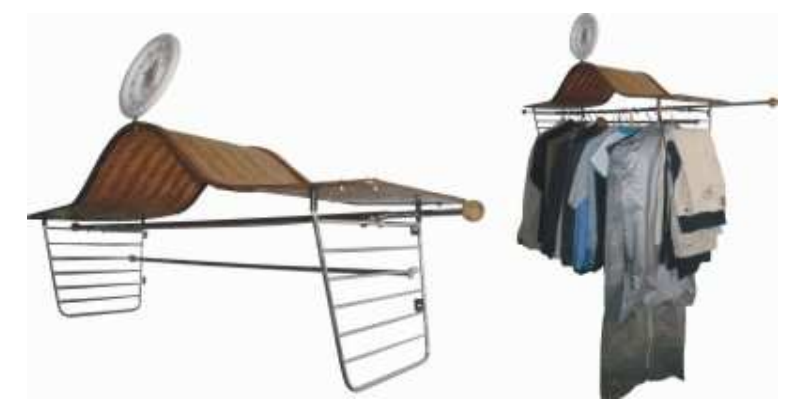

Fig. 2: The figure of product obtaining from new design, was shown

For system work, the engineer team had to participate in for leading to process of Implementation as creation of work piece or product model. For the design work in the step of analytic process, the researcher would use principle of design and product design in implementation. For creation of product model, the consultation with major consultants of project as well as the lecturers teaching the product design, would be administered for making decision in choosing the final model that would be created the real study piece

\section{CONCLUSION}

The findings from this study development, the researcher expected that the designed product model would be useful for different community groups that would be used for real study development and the different community groups would adapt or develop for creating new products, as well as be able to develop study with identity of those communities further.

\section{ACKNOWLEDGEMENT}

The research has been supported generously by the Silpakorn University; The Thailand Research Fund and 
Office of the Higher Education Communication Therese archers would like to express their sincere appreciation for all of the support provided.

\section{REFERENCES}

Krongkaew, M., 2003. The philosophy of sufficiency economy. Kyoto Review. http://kyotoreview.cseas.kyotou.ac.jp/issue/issue3/article_292.html

Doblin, J., 1950. Perspective: A New System for Designers. 1st Edn., Watson-Guptill, New York, ISBN: 10: 0823074196, pp: 68.

Earle, J.H., 1990. Engineering Design Graphics. 6th Edn., Addison-Wesley USA., ISBN: 0201168936, pp: 849 .
Earle, J.H., 2004. Graphics Technology. Prentice Hall, USA., 2nd Edn., ISBN: 10: 0131476432, pp: 560.

Hubel, V. and B.D. Lussow, 1984. Focus on Designing. McGraw-Hill Ryerson, New York, ISBN: 007548661X, pp: 312.

Shimizu, Y., 1990. Creative Market Techniques: In Combination With Mixed Media. Shohan Edn., Books Nippan, Japan, ISBN: 13: 978-4766105803, pp: 131.

Poncharoen, R.T., 2003. Line and Approach in Designing the Product. 2nd Edn., Association for Enhancing Thai-Japan Techno, Bangkok, ISBN: 974-443-004-4, pp: 18. 